\title{
INFLUÊNCIA DA ESPESSURA E INTEGRIDADE DE COBERTURA PLÁSTICA NA GERMINAÇÃO DE Brassica oleracea var. capitata
}

\author{
Amanda Duim Ferreira ${ }^{1}$ \\ Ana Paula Garcia Fernandes ${ }^{2}$ \\ Yohanna Cézar Boroto ${ }^{3}$ \\ Maria Luiza Pereira Pinto ${ }^{4}$ \\ Thainá Ambrósio ${ }^{5}$ \\ Ana Carolina Roos Pinheiro ${ }^{6}$ \\ Douglas Gomes Viana ${ }^{7}$
}

Resumo: Objetivou-se avaliar a influência da espessura e integridade de coberturas plásticas na germinação de sementes de repolho (Brassica oleracea var. capitata) cultivadas principalmente na região serrana do Espírito Santo. O experimento foi conduzido no Laboratório de Tecnologia de Sementes no Campus São Mateus da Universidade Federal do Espírito Santo (UFES), em esquema fatorial $2 \times 2$, com quatro repetições em delineamento inteiramente casualizado. Os tratamentos consistiram de duas espessuras de cobertura dos recipientes $(0,06 \mathrm{~mm}$ - plástico fino; 0,10 $\mathrm{mm}$ - plástico grosso) e a ausência ou presença de furos centralizados na secção superior dos recipientes. As contagens foram feitas do primeiro ao sétimo dia, sendo avaliados os seguintes parâmetros: porcentagem de germinação, índice de velocidade de germinação, tempo médio de germinação, coeficiente de velocidade de germinação e perda de água diária. Verificou-se que não há influência significativa da integridade da cobertura plástica sobre a germinação e é preferível o uso de coberturas plásticas com menor espessura de modo a possibilitar as trocas gasosas.

Palavras-chave: Umidade; Substrato; Oxigênio; Trocas gasosas.

\footnotetext{
1 Graduando do curso de Agronomia/Universidade Federal do Espírito Santo (UFES), Brasil. E-mail: amanda_duim@hotmail.com.

2 Graduando do curso de Agronomia/Universidade Federal do Espírito Santo (UFES), Brasil. E-mail: 18apgf@gmail.com.

3 Graduando do curso de Agronomia/Universidade Federal do Espírito Santo (UFES), Brasil. E-mail: yohannacb@hotmail.com.

4 Graduando do curso de Agronomia/Universidade Federal do Espírito Santo (UFES), Brasil. E-mail: luiza_14p@hotmail.com.

5 Graduando do curso de Agronomia/Universidade Federal do Espírito Santo (UFES), Brasil. E-mail: tatidro@gmail.com.

6 Graduando do curso de Agronomia/Universidade Federal do Espírito Santo (UFES), Brasil. E-mail: carol.pinheiru@gmail.com.

7 Mestrando em Agricultura Tropical, UfES/CEUNES, Brasil. E-mail: d13viana@gmail.com.
} 